Check for updates

Cite this: Nanoscale Adv., 2019, 1, 3929

\title{
Bimetallic $\mathrm{Pd}_{96} \mathrm{Fe}_{4}$ nanodendrites embedded in graphitic carbon nanosheets as highly efficient anode electrocatalysts $\uparrow$
}

\begin{abstract}
Srabanti Ghosh, (D) *a Sandip Bysakh ${ }^{\mathrm{b}}$ and Rajendra Nath Basu*a
A facile route to anchor a nanoalloy catalyst on graphitic carbon nanosheets (GCNs) has been developed for preparing high-performance electrode materials for application in direct alcohol fuel cells (DAFCs). Uniformly dispersed bimetallic Pd-Fe nanoparticles (NPs) with tunable composition have been immobilized on GCNs derived from mesocarbon microbeads (MCMBs) by a one-pot radiolytic reduction method. The Pd-Fe/GCN hybrid shows promising electrocatalytic activity for the methanol, ethanol, ethylene glycol, tri-ethylene glycol and glycerol oxidation reactions in alkaline medium. The as-prepared flower-shape $\mathrm{Pd}_{96} \mathrm{Fe}_{4} / \mathrm{GCN}$ nanohybrids have high mass activity for the ethanol oxidation reaction (EOR), which is $\sim 36$ times (11 A per mg Pd) higher than that of their monometallic counterparts. Moreover, the onset oxidation potential for the EOR on the $\mathrm{Pd}_{96} \mathrm{Fe}_{4} / \mathrm{GCN}$ nanohybrids negatively shifts ca. $780 \mathrm{mV}$ compared to that on commercial $\mathrm{Pd} / \mathrm{C}$ electrocatalysts, suggesting fast kinetics and superior electrocatalytic activity. Additionally, chronoamperometry measurements display good long-term cycling stability of the $\mathrm{Pd}_{96} \mathrm{Fe}_{4} / \mathrm{GCN}$ nanohybrids for the EOR and also demonstrate only $\sim 7 \%$ loss in forward current density after 1000 cycles. The superior catalytic activity and stability may have originated from the modified electronic structure of the Pd-Fe nanoalloys and excellent physicochemical properties of the graphitic nanosheets. The present synthetic route using GCNs as the supporting material will contribute to further design of multimetallic nanoarchitectures with controlled composition and desired

functions for fuel cell applications.
\end{abstract}

Received 21st May 2019

Accepted 16th August 2019

DOI: $10.1039 /$ c9na00317g

rsc.li/nanoscale-advances

\section{Introduction}

Direct alcohol fuel cells (DAFCs) have drawn extensive attention for next generation energy conversion devices and have several advantages, including instantaneous recharging, lighter weight, high specific energy, environmental friendliness and a widespread range of applications, such as in portable electronic equipment, as residential clean energy power sources, and in fuel-cell-powered notebooks, computers, mobile phones, military equipment, etc. ${ }^{1-3}$ Catalysts are the key components for both the anodic oxidation reaction and the cathodic oxygen reduction reaction in fuel cells and up to now, Pt-based nanomaterials are considered as the most active electrocatalysts. ${ }^{\mathbf{4}-6}$ However, the high cost, low abundance, poor reaction kinetics, and loss of electrochemical surface area of Pt catalysts has hindered the commercialization of fuel cells. ${ }^{7}$ As an alternative,

${ }^{a}$ Fuel Cell and Battery Division, CSIR - Central Glass and Ceramic Research Institute, 196, Raja S. C. Mullick Road, Kolkata-700032, India.E-mail: ghosh.srabanti@gmail. com;rnbasu@cgcri.res.in

${ }^{b}$ Materials Characterization Division, CSIR - Central Glass and Ceramic Research Institute, 196, Raja S. C. Mullick Road, Kolkata-700032, India

$\dagger$ Electronic supplementary information (ESI) available. See DOI: 10.1039/c9na00317g researchers developed earth-abundant Pd metal-based electrocatalysts for alcohol oxidation in alkaline media. ${ }^{8-10}$ The engineering of the shape and composition of Pd-based materials at the nanoscale provides improved catalytic activity and stability. ${ }^{8-12}$ In this regard, bimetallic nanostructures display remarkably improved catalytic activity compared with the corresponding monometallic nanocrystals due to the modified electronic structures and ligand effects between the different components. ${ }^{\mathbf{1 3 , 1 4}}$ Various bi/trimetallic Pd-based electrocatalysts (such as $\mathrm{Pd}-\mathrm{Ag}, \mathrm{Pd}-\mathrm{Pt}, \mathrm{Pd}-\mathrm{Ni}, \mathrm{Pd}-\mathrm{Cu}, \mathrm{Pd}-\mathrm{Au}, \mathrm{Pd}-\mathrm{Pt}-\mathrm{Au}$, etc.) showed superior electrocatalytic activity for the methanol (MOR) or ethanol oxidation reaction (EOR). ${ }^{15-21}$ Very recently, our group demonstrated that conducting polymer nanofiber supported Pd based trimetallic nanoalloys are highly promising electrocatalysts for the EOR in alkaline media. ${ }^{22}$ Particularly, Pd or Pt-based core-shell-type noble metal nanostructures have been widely employed as efficient anode catalysts for the alcohol oxidation reaction. ${ }^{23-31}$ However, fabrication of such nanostructures involves complicated multistep processes, which make the process difficult to scale up. Moreover, these Pd-based anode electrocatalysts still suffer from low activity and high cost, which endorses the need for a facile strategy to produce advanced electrocatalysts. To obtain higher utilization efficiency of Pd in alcohol fuel electrooxidation, transition- 
metal-based catalysts, such as $\operatorname{PdM}(\mathrm{M}=\mathrm{Sn}, \mathrm{Cu}, \mathrm{Ni}, \mathrm{Co}$, etc. $)$ alloy or core/shell NPs, were tested and they showed noticeable potential for enhancing the catalytic activity due to the optimized electronic and structural effects. ${ }^{32-35}$ So far, bimetallic PtFe nanocrystals have been synthesized and they generally exhibit higher electrocatalytic activity. For example, Guo et al. ${ }^{36}$ developed a facile solution-phase self-assembly method to deposit FePt NPs on a graphene surface, and the resulting catalyst shows enhanced catalytic activity and durability for the ORR in acidic medium. Mohammad and co-workers reported a binary $\mathrm{FeO}_{x} / \mathrm{Pt}$ nanoanode for formic acid electro-oxidation and proposed that the catalyst's activation, conducted through a surface reconstruction for the Pt surface sites, makes the facets favourable for oxidation. ${ }^{37}$ In another example, PtFe nanodendrites with high-index facets showed higher reactivity for oxygen reduction. ${ }^{38}$ Very recently, Guo and co-workers ${ }^{39}$ fabricated ultrafine $\mathrm{Pt}-\mathrm{Fe}$ nanowires for the oxidation of ethylene glycol and glycerol, and their activity was 3.9 and 2.5 times greater than that of commercial $\mathrm{Pt} / \mathrm{C}$, respectively. Although Pt-Fe has been considered as one of the best catalysts, its Pd-based counterpart (Pd-Fe) has not been well studied for the EOR in alkaline media. Notably, noble metal nanodendrites with a branched structure generally show better activity and durability for the catalytic reaction due to their large surface area, unusual interconnected as well as porous structure and fast mass transfer. ${ }^{\mathbf{4 0 - 4 2}}$ To the best of our knowledge, there have been no reports on the preparation of bimetallic Pd-Fe nanodendrites and their electrocatalytic behaviour remains unknown so far.

Furthermore, the utilization of noble metal nanostructures can be improved by using carbonaceous porous materials as the most suitable catalyst supporting matrix due to their high electrical conductivity, chemical stability, large accessible surface area and rapid ion transfer rate. ${ }^{43}$ So far, various porous carbons with different morphologies have been widely investigated, such as common carbon blacks including acetylene black, Vulcan XC-72, ketjen black, porous carbon nanospheres, carbon nanosheets, carbon nanofibers, graphene, conducting polymers, etc. ${ }^{\mathbf{4 4}, \mathbf{4 5}}$ Among these carbon materials, two dimensional (2D) carbon nanomaterials such as graphene and 2D carbon nanosheets have great potential as electrode supports, having unique properties, including high electrical conductivity, large surface area and a porous layer structure. ${ }^{46-48}$ For example, Lee's group, Chen's group and Lu's group synthesized Pt-Pd alloy nanostructures supported on graphene, which exhibited high catalytic performance for the EOR. ${ }^{49-51}$ According to Chen's report, graphene enhances the catalytic activity of the Pt-Pd alloy nanostructures for the EOR due to the improved electrocatalyst-electrode electron transfer pathway. Xu's group found that graphene supported ternary PtAuRu alloys exhibited excellent electrocatalytic activity for ethanol oxidation..$^{52}$ A series of multimetallic electrocatalysts have also been developed for alcohol oxidation based on a graphene support in order to adjust the chemical/electrical structures of the supported nanostructures, which can facilitate charge transfer and ionic interchange. ${ }^{53-56}$ Despite this success, graphene usually suffers from serious agglomeration and restacking because of strong van der Waals interlayer interactions, which certainly lower the specific surface area. ${ }^{57,58}$ Due to the weak interactions between surface graphene and metal species, it is difficult to get highly dispersed bimetallic NPs on graphene, and further modification of the graphene surface with electron-rich functional groups/sites may improve the binding ability of metal precursors. Hence, the synthesis and functionalization process of graphene are relatively complicated and high-cost, which limits its practical application. ${ }^{59}$ Interestingly, 2D carbon nanosheets with graphene-like layered structure materials possess high electrical conductivity, a large number of active sites and high effective surface area, which make them ideal as an electrocatalyst support. ${ }^{60,61}$ Many advanced techniques, including activation, helium ion bombardment, the template method, mechanical/chemical exfoliation, chemical vapour deposition, etc., have been developed to fabricate carbonaceous nanosheets but establishing an efficient and facile synthesis methodology for $2 \mathrm{D}$ porous carbon nanosheets would be of great benefit for their large scale production. ${ }^{62-65}$ Mesocarbon microbeads (MCMBs) are one of the commercially available conducting carbon materials with good thermal and chemical stability and high crystallinity that are widely utilized for cost-effective electromagnetic interference shielding application, supercapacitors, and as an anode material in lithium-ion batteries and a supporting material for fuel cell applications. ${ }^{66,67}$ It is worth mentioning that there is no report in the literature on the synthesis of carbon nanosheets using MCMBs as the carbon source and this motivated us to develop a facile one-pot synthesis for metal deposited carbon nanosheets as multifunctional electrocatalysts.

Radiolysis is a promising alternative colloidal technique for the synthesis of nanoparticles with a narrow size distribution due to controlled particle nucleation and growth processes. ${ }^{\mathbf{6 8 , 6 9}}$ Herein, we reported an efficient route to simultaneously fabricate Pd-Fe nanoalloys and deposit them on 2D graphene-like carbon nanosheets (GCNs) derived from MCMBs by a radiolytic method and reduction of Pd and Fe complexes. The highly dispersed bimetallic Pd-Fe NPs supported on graphitic nanosheets show exceptionally high catalytic activity toward alcohol electrooxidation in alkaline media, which has potential for application in fuel cells. The resulting metal alloy nanostructure and carbon nanohybrids were then characterized using common techniques, such as transmission electron microscopy (TEM), high-angle annular dark-field scanning transmission electron microscopy (HAADF-STEM), elemental mapping analysis, X-ray diffraction (XRD), and X-ray photoelectron spectroscopy (XPS) to confirm the formation of nanohybrids with controlled compositions by one-step radiolytic reduction.

\section{Experimental section}

\subsection{Materials and reagents}

Palladium(II) acetylacetonate, iron(III) acetylacetonate, 2-propanol, ethanol ( $\geq 99 \%$ for HPLC), $\mathrm{KOH}(97 \%), \mathrm{HCl}$, Nafion ${ }^{\circledR}$ suspension (5 wt\%) and acetone were purchased from SigmaAldrich. Mesocarbon microbeads (MCMBs) were purchased from MTI Corporation, CA, USA. All of the reagents employed in 
the present study were used as received without further purification. Ultrapure water (Millipore System, $18.2 \mathrm{M} \Omega \mathrm{cm}$ ) was used as the solvent.

\subsection{Synthetic procedures}

Metal nanoparticle deposition on MCMBs. Metal nanoparticles were deposited on mesocarbon microbeads by using steady state gamma irradiation. In a typical experiment, $1 \mathrm{mg}$ $\mathrm{mL}^{-1}$ MCMB solution was mixed with $1 \mathrm{mM}$ palladium(II) acetylacetonate, and iron(III) acetylacetonate solution and then deaerated under a $\mathrm{N}_{2}$ flow. This final solution was irradiated in Co-60 gamma irradiation chamber at a dose rate of $10.8 \mathrm{kGy} \mathrm{h}^{-1}$ (dose, $55 \mathrm{kGy} \mathrm{h}^{-1}$ ). Finally, the mixture was centrifuged and washed with ethanol and the obtained precipitate was then dried at $60{ }^{\circ} \mathrm{C}$. Similarly, bimetallic Pd-Fe/GCN with different compositions was prepared by selecting suitable mass ratios.

\subsection{Characterization}

High-resolution transmission electron microscopy (HRTEM) images were obtained with a Tecnai G2 30ST (FEI) highresolution transmission electron microscope operating at 300 $\mathrm{kV}$. The X-ray diffraction (XRD) patterns of the catalysts were recorded on a Philips X'Pert X-ray diffractometer (The Netherlands) with $\mathrm{Cu} \mathrm{K} \alpha$ radiation $(\lambda=1.54056 \AA)$. XPS measurement was performed on a PHI 5000 VersaProbe II spectrophotometer (Physical Electronics Inc., USA) with $\mathrm{Al} \mathrm{K} \mathrm{K}_{\alpha}(\sim 1486.6 \mathrm{eV}) \mathrm{X}$-rays. Charge correction was made by taking $\mathrm{C}$ 1s spectra as the standard (284.5 eV). Raman spectra were collected using a JOBIN YVON HR800 Confocal Raman system employing a $632.8 \mathrm{~nm}$ laser beam. The spectra were recorded using a $20 \times$ objective and accumulated for $30 \mathrm{~s}$. The composition of the nanohybrids was determined using a Spectro Ciros Vision inductively coupled plasma atomic-emission spectroscopy (ICPAES) instrument, Spectro GmbH, Germany. The actual metal loading in each nanohybrid was determined by ICP-AES to be $\mathrm{Pd}_{100} / \mathrm{GCN}(9 \pm 1 \%), \mathrm{Pd}_{96} \mathrm{Fe}_{4} / \mathrm{GCN}$ ( $\left.4 \pm 0.15 \%\right), \mathrm{Pd}_{91} \mathrm{Fe}_{9} / \mathrm{GCN}$ (3.4 $\pm 28 \%$ ), $\mathrm{Pd}_{85} \mathrm{Fe}_{15} / \mathrm{GCN}(1.9 \pm 0.5 \%)$, and $\mathrm{Pd}_{77} \mathrm{Fe}_{23} / \mathrm{GCN}$ $(1.45 \pm 0.12 \%)$.

\subsection{Electrocatalytic experiments}

All electrochemical measurements were carried out on a galvanostat-potentiostat (PGSTAT302N, Autolab, Netherlands). A conventional three-electrode system was used, with platinum wire as the counter electrode, a modified glassy carbon electrode (Carbone Lorraine $11 \mathrm{~mm}$ diameter) as the working electrode, and a $\mathrm{Ag} / \mathrm{AgCl}(\mathrm{Hg} / \mathrm{HgO})$ electrode as the reference electrode. The electrolyte solution was purged with argon gas in order to remove dissolved oxygen. Prior to surface coating, the surface of a glassy carbon electrode was polished with $\alpha$ alumina powder. Then $5 \mu \mathrm{L}$ of nanohybrid or commercial catalysts (20\% Pd or Pt on Vulcan XC-72, JM) were deposited on the surface of the GC electrode and dried before electrochemical measurement. Cyclic voltammetry (CV) was carried out in $0.5 \mathrm{M} \mathrm{KOH}$ electrolyte and in the presence of alcohols such as ethanol, methanol, ethylene glycol, tri-ethylene glycol, and glycerol, at a scan rate of $50 \mathrm{mV} \mathrm{s}^{-1}$. Electrochemical impedance spectroscopy (EIS) measurements were recorded at a potential of $0.1 \mathrm{~V}$. The charge transfer resistance $\left(R_{\mathrm{ct}}\right)$ was measured by circle fitting from EIS measurement by applying an AC voltage with $10 \mathrm{mV}$ amplitude in a frequency range from 0.1 to $10 \mathrm{kHz}$. The electrochemically active surface area (ECSA, $\mathrm{m}^{2}$ $\left.\mathrm{g}^{-1} \mathrm{Pd}\right)$ is usually determined using the formula ECSA $=Q$ / $\left(0.405 \times m_{\mathrm{pd}}\right)$, where $Q$ represents the coulombic charge corresponding to the reduction peak area of $\mathrm{PdO}(\mathrm{mC})$, and $m_{\mathrm{pd}}$ is the mass of Pd loading ( $\mathrm{mg}$ ) on the electrode, respectively. The charge required for the reduction of the PdO ( $\left.Q_{\text {PdO-red }}\right)$ monolayer has been considered as $405 \mu \mathrm{C} \mathrm{cm}^{-2}$.

\section{Results and discussion}

Pd-Fe NPs were loaded on the graphitic nanosheets derived from mesocarbon microbeads by using a facile radiochemical method. Briefly, MCMBs were dispersed in a water-propanol mixture by ultra-sonication and mixed with palladium and iron salts in a pre-calculated $\mathrm{Pd} / \mathrm{Fe}$ molar ratio at room temperature and irradiated at a dose rate of $10.8 \mathrm{KGy} \mathrm{h}^{-1}$ (Scheme 1). Notably, metal ions can easily be adsorbed on the interfaces of MCMBs and then be reduced to form NPs and MCMBs, subsequently being converted into graphitic carbon nanosheets (GCNs). Finally, graphitic carbon nanosheet supported bimetallic Pd-Fe NPs, denoted as $\mathrm{Pd}_{1-x} \mathrm{Fe}_{x} / \mathrm{GCN}(x$, molar ratio of $\mathrm{Fe}$ ), formed in the solution. The $\gamma$-irradiation creates electrons, $\mathrm{H}$ atoms, and hydroxyl radicals from the water, and $\mathrm{Pd}^{2+}$ and $\mathrm{Fe}^{3+}$ were reduced to form Pd-Fe nanoalloys. ${ }^{70}$

The metal ions were reduced to lower oxidation states or zero valence state by strong reductants, $\mathrm{e}_{\mathrm{aq}}{ }^{-}$and $\mathrm{H}$, produced by water radiolysis, and oxidizing radiolysis products, particularly $\mathrm{OH}$, were removed by adding scavengers (2-propanol) to prevent the back-oxidation of the zero-valence metal to a cation (eqn (1) and (2)). Due to the fast electronic process in radiolysis, the electron reduced a sufficiently high concentration of both metal ions to generate nanoalloy clusters at a high dose rate. ${ }^{71,72}$ Hence, electrons $\left(\mathrm{e}_{\mathrm{aq}}{ }^{-}\right.$) can reduce $\mathrm{Pd}(\mathrm{II})$ and $\mathrm{Fe}(\mathrm{III})$ ions into lower-state $\mathrm{Pd}(\mathrm{I})$ and $\mathrm{Fe}(\mathrm{II})$ ions and then, neutral palladium and iron atoms, followed by growth of nuclei and co-deposition of metal atoms to form bimetallic alloy clusters (eqn (3)-(10)): ${ }^{73,74}$

$$
\begin{gathered}
\mathrm{H}_{2} \mathrm{O} \rightarrow \mathrm{e}_{\mathrm{aq}}{ }^{-}, \mathrm{H}_{3} \mathrm{O}^{+}, \mathrm{H}^{\cdot}, \mathrm{OH}^{\cdot}, \mathrm{H}_{2} \mathrm{O}_{2} \\
\left(\mathrm{CH}_{3}\right)_{2} \mathrm{CHOH}+\mathrm{OH}^{\cdot}\left(\text { or } \mathrm{H}^{\cdot}\right) \rightarrow\left(\mathrm{CH}_{3}\right)_{2} \mathrm{C}^{\cdot} \mathrm{OH}+\mathrm{H}_{2} \mathrm{O}\left(\mathrm{or}_{2}\right)(2) \\
\mathrm{e}_{\mathrm{aq}}{ }^{-}+\mathrm{M}^{+} \rightarrow \mathrm{M}^{0}(\mathrm{M}=\mathrm{Pd}, \mathrm{Fe}) \\
\left(\mathrm{CH}_{3}\right)_{2} \mathrm{C}^{\cdot} \mathrm{OH}+\mathrm{M}^{+} \rightarrow\left(\mathrm{CH}_{3}\right)_{2} \mathrm{CO}+\mathrm{M}^{0}+\mathrm{H}^{+} \\
\mathrm{Pd}^{\mathrm{II}}+\mathrm{e}_{\mathrm{aq}}{ }^{-} \rightarrow \mathrm{Pd}^{\mathrm{I}} \\
\mathrm{Pd}^{\mathrm{II}}+\left(\mathrm{CH}_{3}\right)_{2} \mathrm{C}^{\cdot} \mathrm{OH} \rightarrow \mathrm{Pd}^{\mathrm{I}}+\left(\mathrm{CH}_{3}\right)_{2} \mathrm{CO}+\mathrm{H}^{+} \\
2 \mathrm{Pd}^{\mathrm{I}} \rightarrow \mathrm{Pd}^{0}+\mathrm{Pd}^{\mathrm{II}} \\
n \mathrm{Pd}^{0} \rightarrow\left(\mathrm{Pd}_{n}\right. \\
\mathrm{Fe}^{\mathrm{III}}+\mathrm{e}_{\mathrm{aq}}{ }^{-} \rightarrow \mathrm{Fe}^{\mathrm{II}}\left(E^{0}=+0.77 \mathrm{~V}\right)
\end{gathered}
$$




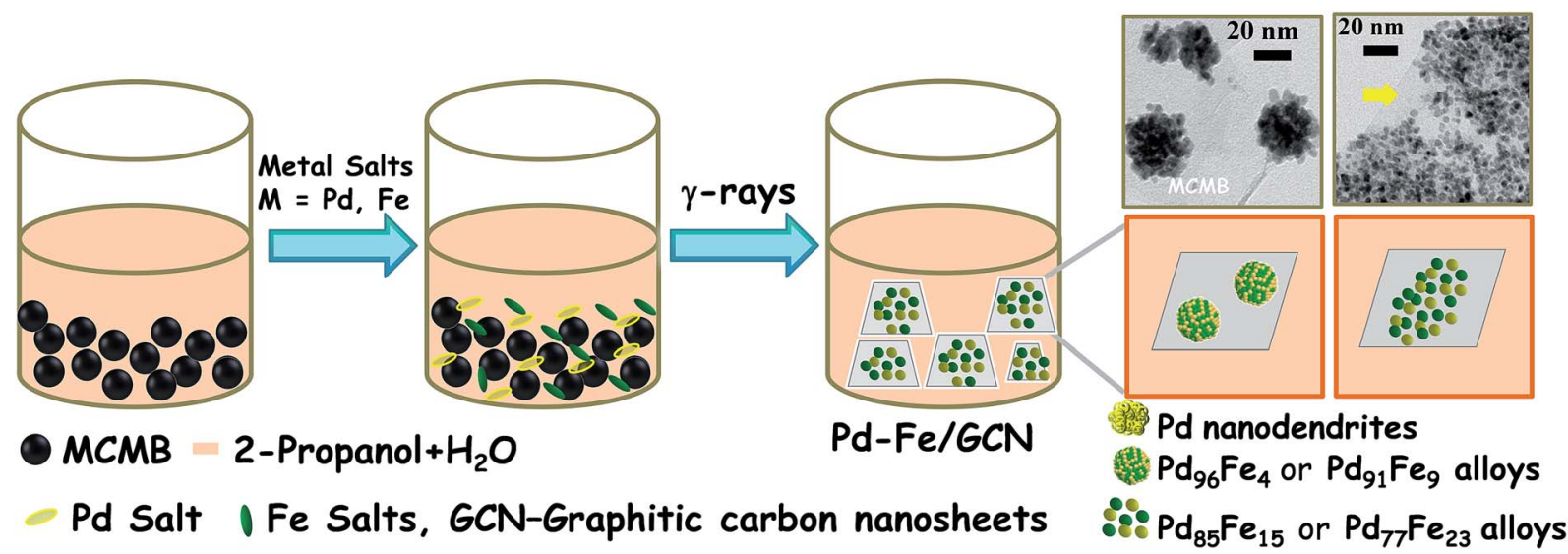

Scheme 1 Schematic illustration of radiochemical synthesis of the Pd-Fe bimetallic alloy on carbon nanosheets.

$$
\mathrm{Fe}^{\mathrm{III}}+3 \mathrm{e}_{\mathrm{aq}}{ }^{-} \rightarrow \mathrm{Fe}^{0}\left(E^{0}=-0.04 \mathrm{~V}\right)
$$

Clearly, the scanning electron microscopy (SEM) image of MCMBs exhibits porous 3D frameworks constructed from graphene layers with random open pores. The size of the MCMBs is in the range of $5-10 \mu \mathrm{m}$, while some smaller ones are less than $1 \mu \mathrm{m}$ in size as shown in Fig. S1a, ESI. $\dagger$ After radiolysis, MCMBs converted into graphene-like carbon nanosheets as shown in transmission electron microscopy (TEM) and high resolution TEM (HRTEM) images (Fig. S1b and c, ESI $\dagger$ ), which show ultrathin structures with a highly crumpled morphology. After radiochemical reduction of the Pd complex in the presence of MCMBs, the reaction leads to the formation of spherical Pd assembled nanostructures deposited on graphitic carbon nanosheets. The representative TEM images of the $\mathrm{Pd}_{100} / \mathrm{GCN}$ nanohybrid in Fig. 1a and b show that the Pd nanoflowers with an average particleagglomerate size of $\sim 40 \mathrm{~nm}$ are uniformly deposited on the carbon nanosheet support. The HRTEM image (Fig. 1c) shows that each nanostructured agglomerate is composed of many single crystalline grains or nanocrystals. The interplanar distance in the lattice fringes of one such nanocrystal has been measured to be $0.22 \mathrm{~nm}$, which corresponds to the (111) plane of metallic Pd. The selected area electron diffraction (SAED) pattern recorded from one of the Pd nanostructures shows diffraction rings corresponding to the various lattice planes of the face centred cubic crystal structure of palladium (Fig. 1d). ${ }^{11,12}$
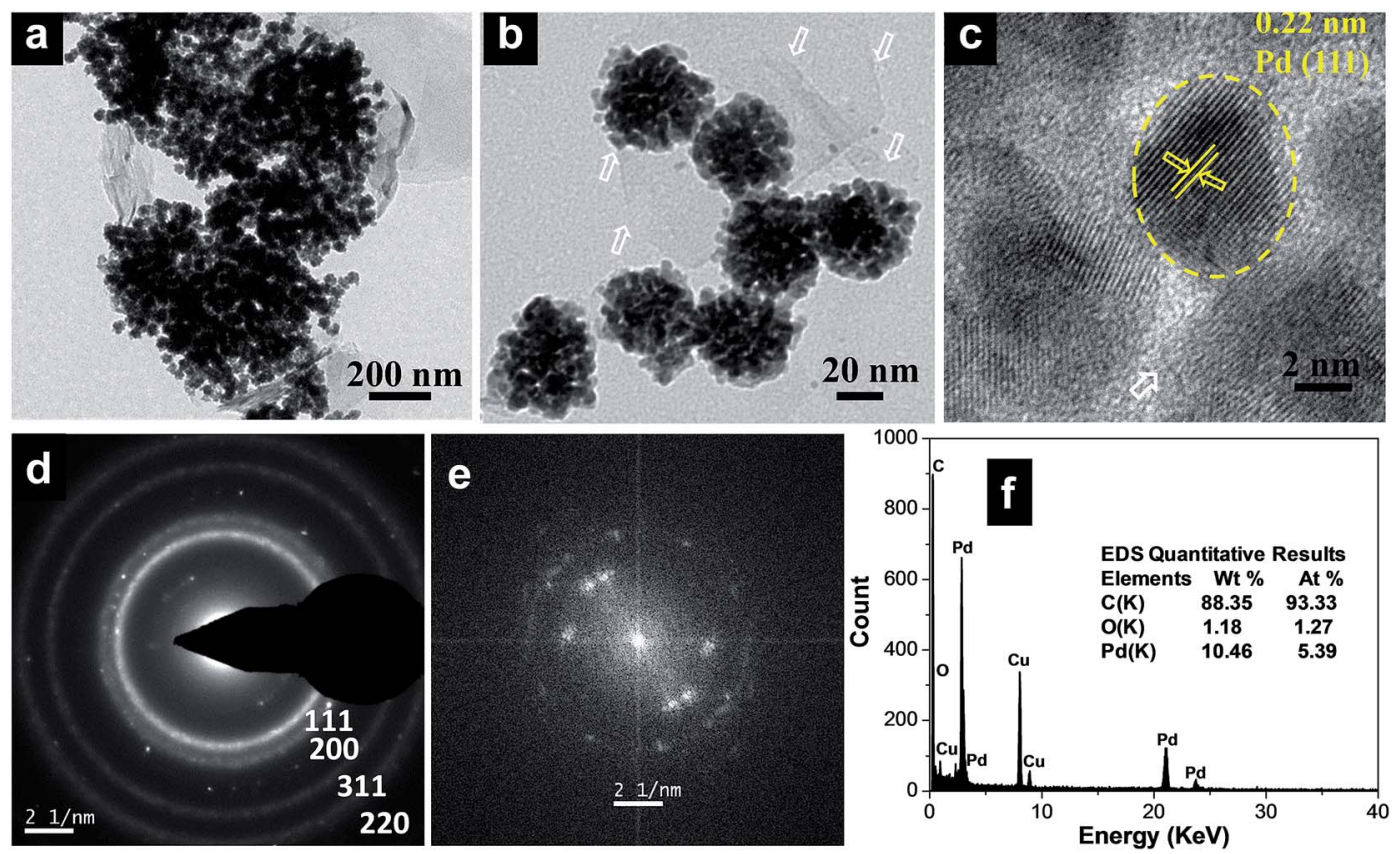

Fig. 1 ( $a$ and b) Transmission electron micrographs of the $\mathrm{Pd}_{100} / \mathrm{GCN}$ nanohybrid at two different magnifications, (c) HRTEM image of palladium nanoparticles, (d) SAED pattern and (e) FFT and (f) EDS spectrum of the $\mathrm{Pd}_{100} / \mathrm{GCN}$ nanohybrid. The white arrows represent the thin sheets of graphitic carbon. 
Furthermore, the fast Fourier transform (FFT) as given in Fig. 1e, obtained from the HRTEM image (Fig. 1c), shows three pairs of bright spots corresponding to the (111) and (200) lattice fringes of cubic Pd in three different nanocrystals, suggesting that the flower-like individual nanoclusters are polycrystalline in nature and consist of fine Pd nanocrystals. The formation of such metal nanoflower structures by $\gamma$-radiation can be rationalized through the slow reduction kinetics particularly at the seeding stage which leads to the formation of $3 \mathrm{D}$ nanostructures. $^{75}$ Energy-dispersive X-ray spectroscopy (EDS) analysis shows the presence of $\mathrm{C}$ and Pd (Fig. 1f).

Pd-Fe bimetallic nanoparticles with different compositions were also prepared using MCMBs as a supporting material through a reaction similar to that used for the Pd nanoflowers, where the amount of Pd and Fe precursors (Pd : Fe, $95: 5,90: 10$, $85: 15$, and $75: 25)$ in the initial solution was varied while keeping the total volume of the solution unchanged. Interestingly, under similar synthetic conditions of the nanoalloy, only by enhancing the concentration of Fe precursors, which can be used as the shape controller, Pd-Fe alloy nanoflowers can be obtained with up to 9 at\% Fe. As displayed in Fig. 2a and b, the as-prepared hybrids consist of Pd-Fe bimetallic nanoflowers with an average particle size of $50 \mathrm{~nm}$ and $54 \mathrm{~nm}$, respectively.

With further increase of Fe concentration from 10 to $25 \%$, strikingly uniform sized spherical nanoclusters of Pd-Fe alloy
( $\sim 3.3 \mathrm{~nm}$ and $\sim 5 \mathrm{~nm}$ for $\mathrm{Pd}_{85} \mathrm{Fe}_{15}$ and $\mathrm{Pd}_{77} \mathrm{Fe}_{23}$ compositions, respectively) formed on the carbon nanostructures as shown in Fig. 2c and d. TEM and high angle annular dark-field scanning TEM (HAADF-STEM) images of the $\mathrm{Pd}_{91} \mathrm{Fe}_{9} / \mathrm{GCN}$ nanohybrids reveal the random distribution and severe aggregation of smaller NPs with the nanoflower structure (Fig. 3a).

The fringes in the HRTEM image (Fig. 3b) are separated by $0.225 \mathrm{~nm}$, close to the (111) lattice spacing of the $\mathrm{L}_{0}$ ordered structure of $\mathrm{Pd}-\mathrm{Fe}$. The superlattice structure resulting from $\mathrm{L} 1_{0}$ type atomic ordering can be clearly seen in the HRTEM image of the Pd-Fe nanoparticles, which is consistent with earlier reports. ${ }^{76,77}$ It has been proposed in the literature that the $\mathrm{L} 1_{0}$ superlattice crystal structure results from the alternate stacking of $\mathrm{Fe}$ and $\mathrm{Pd}$ in the (001) direction in the $\mathrm{L} 1_{0}$ type ordering of the two different atomic species and the (220) atomic planes also possess an alternate stacking sequence of Fe and Pd in the (110) direction. In addition, the HAADF-STEM image (Fig. 3c) together with the EDS spectrum-image elemental mapping analysis of Pd (Fig. 3d) and Fe (Fig. 3e) shows that Fe (violet) is distributed on Pd atoms (green) throughout the whole area in the 3D alloy nanostructures. Hence, the STEM-EDS elemental mapping analysis within the resolution of the TEM used in the present work suggests that the elements Pd and Fe are distributed with fair uniformity within the nanoflowers. The bulk composition of the as-synthesized nanohybrids was determined
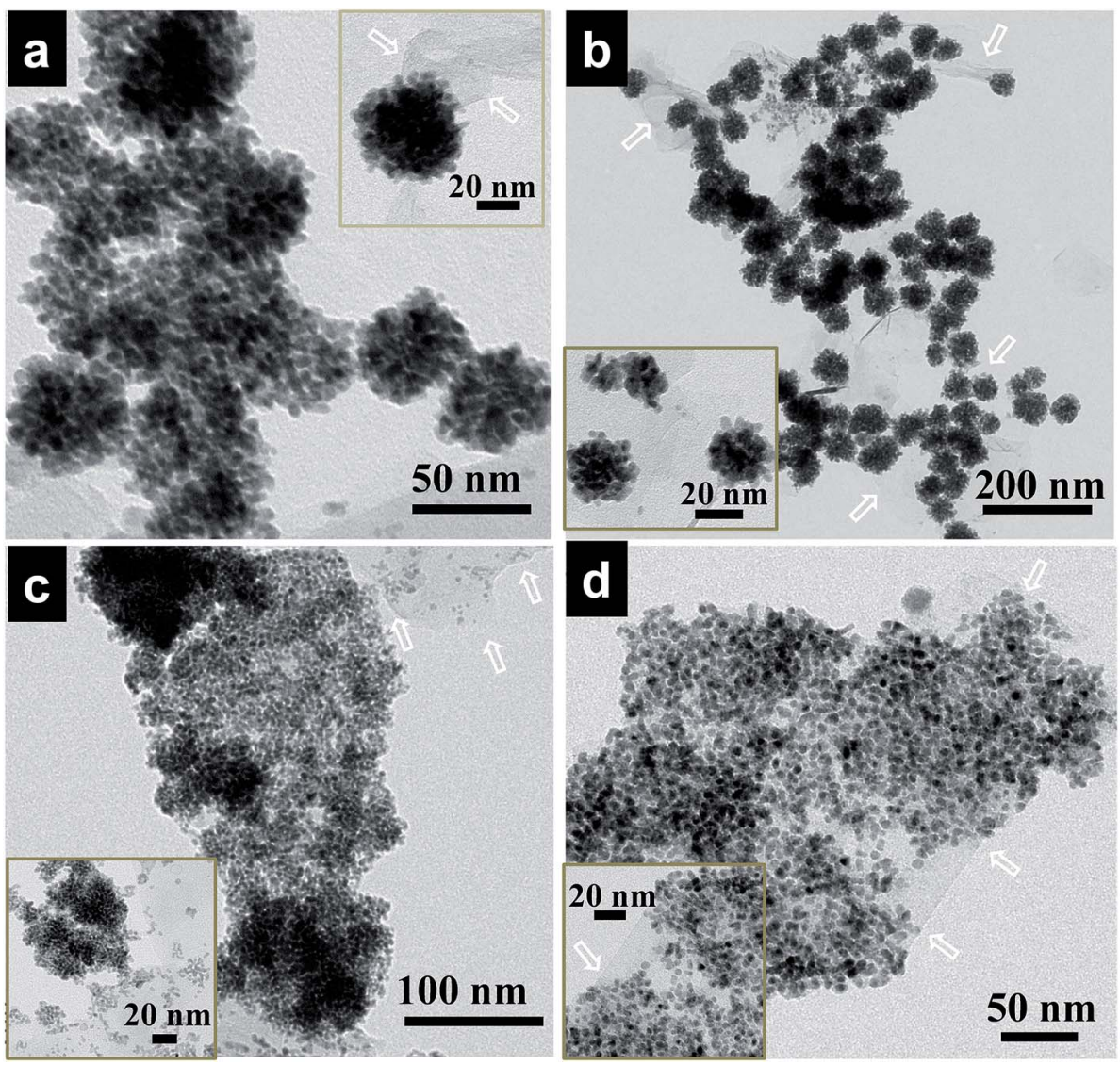

Fig. 2 TEM images of Pd-Fe nanoalloys deposited on graphitic carbon nanosheets. (a) $\mathrm{Pd}{ }_{96} \mathrm{Fe}_{4} / \mathrm{GCN}$, (b) $\mathrm{Pd} \mathrm{d}_{91} \mathrm{Fe}_{9} / \mathrm{GCN}$, (c) $\mathrm{Pd} \mathrm{d}_{85} \mathrm{Fe}_{15} / \mathrm{GCN}$, and (d) $\mathrm{Pd}_{77} \mathrm{Fe}_{23} / \mathrm{GCN}$ nanohybrids. Inset: the corresponding Pd-Fe nanoalloys at high magnification. The white arrows represent the thin sheets of graphitic carbon. 

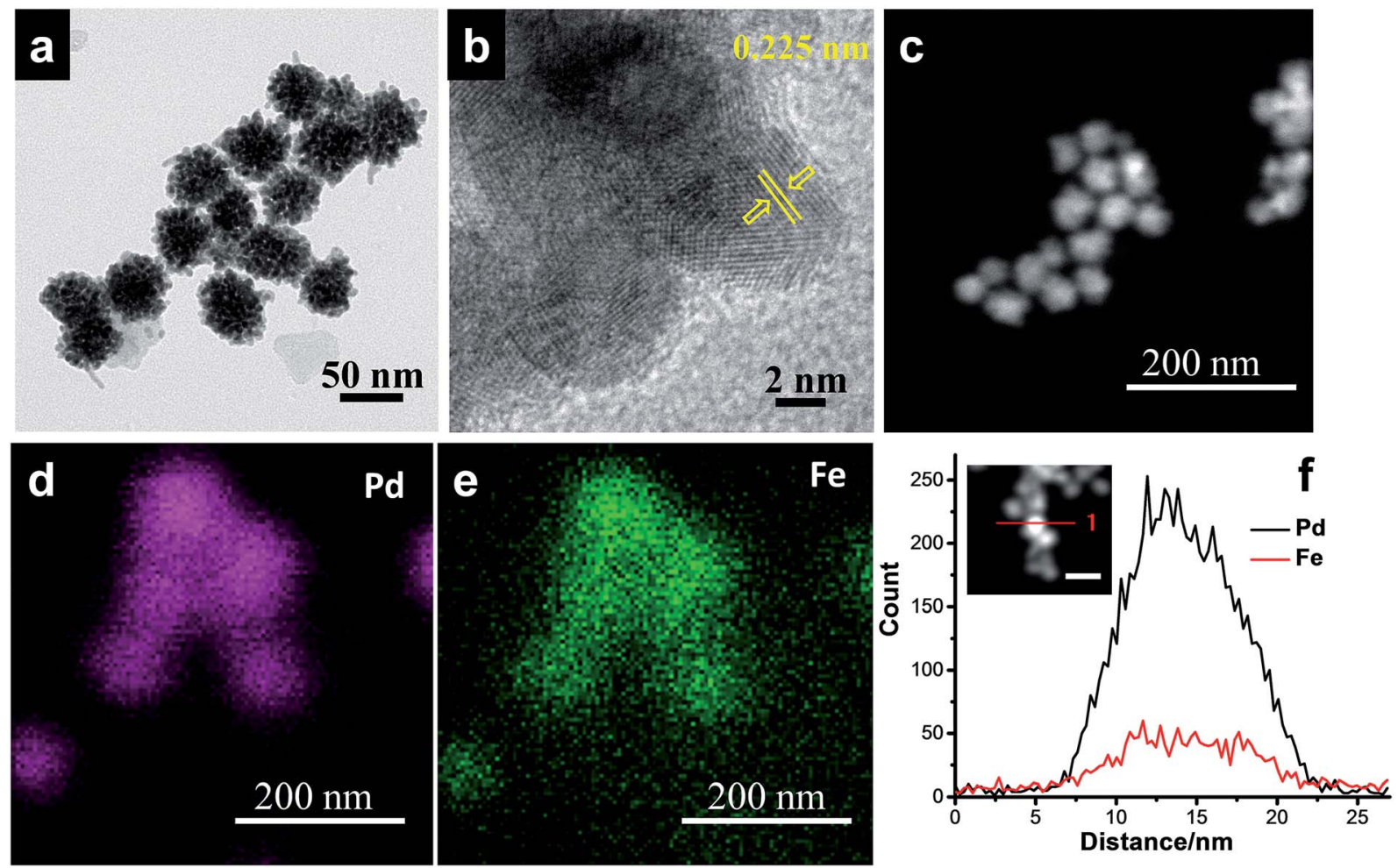

Fig. 3 (a) TEM, (b) HRTEM, and (c) HAADF-STEM images, and (d and e) elemental mapping and (f) EDS line scanning profiles of the Pd ${ }_{91} F e_{9} / G C N$ nanohybrids.

by inductively coupled plasma atomic emission spectroscopy (ICP-AES) analysis and is in agreement with our initial proposed composition (Table S1†). Similarly, the EDS line scanning profiles across a single particle (Fig. 3f, inset) also reveal that the nanoflower consists of Pd and Fe.

Upon further increasing the precursor amount of Fe in the initial solution, spherical nanoparticles are formed instead of nanoflowers or nanoclusters. In contrast, the TEM and HAADFSTEM images of the $\mathrm{Pd}_{77} \mathrm{Fe}_{23} / \mathrm{GCN}$ nanohybrids indicate the uniform dispersion of $\mathrm{Pd}_{77} \mathrm{Fe}_{23}$ bimetallic alloy nanoparticles on the GCNs with an average particle size of $5 \pm 1 \mathrm{~nm}$ (as shown in Fig. S2a and c, ESI $\dagger$ ) and Fig. S2b $\dagger$ shows the typical HRTEM image of a single nanoparticle. The interval between the two lattice fringes is $0.225 \mathrm{~nm}$, which corresponds well to the (001) plane of the ordered $\mathrm{Pd}-\mathrm{Fe} \mathrm{L} \mathbf{1}_{0}$ structure and is consistent with the ideal atomic arrangement. ${ }^{78}$ The HAADF-STEM image and STEM-EDS elemental mapping suggest that the nanoparticles consist of Pd and Fe (Fig. S2c-e, ESI†). The results of both ICPAES and EDS show that the nanoparticles are made of Pd and Fe. From ICP-AES analysis, the atomic ratio of Pd and Fe was almost $3.3: 1$, close to the theoretical proportion of $3: 1$. Moreover, the EDS line scanning profiles across a single particle (Fig. S2d, ESI $\dagger$ ) also illustrates the formation of a uniform alloy composition within the individual Pd-Fe nanoparticles.

The X-ray diffraction (XRD) pattern of pristine MCMBs shows a very sharp diffraction peak at $2 \theta=26^{\circ}$ which is the characteristic peak of graphite and corresponds to the diffraction of the (002) plane, with the interlayer distance, $d_{002}=0.337 \mathrm{~nm}$ (Fig. 4). ${ }^{79}$
After radiolytic reduction, the strong diffraction pattern observed in all nanohybrids indicates the presence of graphitic carbon. The XRD patterns of the as-synthesized Pd-Fe/GCN shows the characteristic peaks of Fe-Pd particles that belong to a chemically disordered cubic structure. The (111) peak position in Fe-Pd appears at a slightly higher scattering angle compared to that of Pd nanoparticles, indicating the formation of a Pd-Fe alloy. ${ }^{80,81}$

XPS analysis of the as-synthesized Pd-Fe/GCN was conducted to elucidate the composition and oxidation state of metal present in the nanohybrids as shown in Fig. 5 . The wide scan

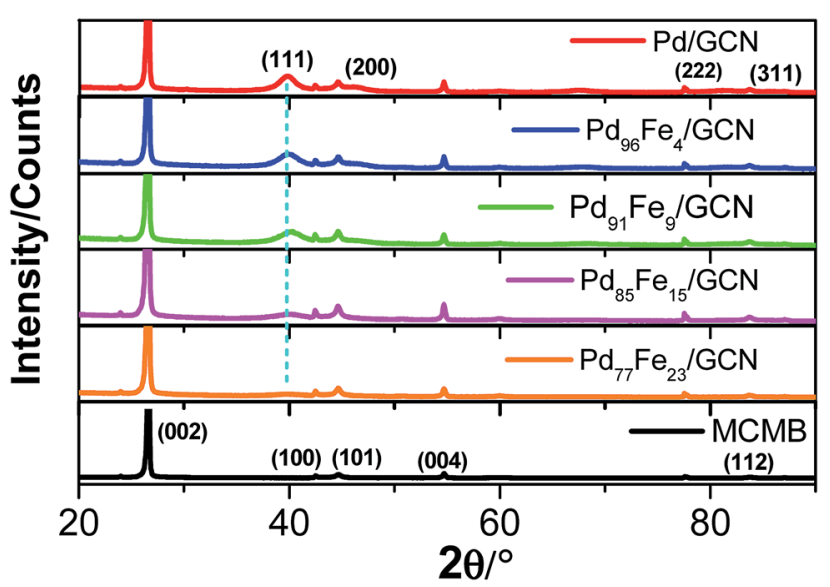

Fig. 4 XRD patterns of the nanohybrid samples compared with that of MCMBs. 
XPS spectrum of the $\mathrm{Pd}_{96} \mathrm{Fe}_{4} / \mathrm{GCN}$ nanohybrids (Fig. 5a) reveals the presence of $\mathrm{C}, \mathrm{O}, \mathrm{Pd}$, and Fe. The signals at 335.3 and $340.4 \mathrm{eV}$ correspond to the $\mathrm{Pd} 3 \mathrm{~d}_{5 / 2}$ and $\mathrm{Pd} 3 \mathrm{~d}_{3 / 2}$ levels of $\mathrm{Pd}^{0}$, while the signals at small doublets around 336.7 and 342.1 are associated with the $\mathrm{Pd} 3 \mathrm{~d}_{3 / 2}$ and $\mathrm{Pd} 3 \mathrm{~d}_{5 / 2}$ levels of PdO (Fig. $5 \mathrm{~b}$ ). The Fe $2 \mathrm{p}$ spectrum is composed of $\mathrm{Fe} 2 \mathrm{p}_{3 / 2}$ and $\mathrm{Fe} 2 \mathrm{p}_{1 / 2}$ with binding energy at $710.6 \mathrm{eV}$ and 723.9 which further confirmed the presence of di- and trivalent iron atoms as shown in Fig. 5c.

The satellite peaks of $719 \mathrm{eV}$ and $\sim 732 \mathrm{eV}$ at higher binding energy correspond to $\mathrm{Fe}^{3+}$ in $\alpha-\mathrm{Fe}_{2} \mathrm{O}_{3}$ due to charge transfer as reported earlier. ${ }^{82,83}$ Moreover, the XPS peak at 285-286 eV corresponding to the $\mathrm{C} 1 \mathrm{~s}$ region was attributed to carbon nanosheets (Fig. 5d). The Raman spectrum of the metal nanoparticle deposited graphitic nanosheets shows major peaks of D and $\mathrm{G}$ bands at $1346 \mathrm{~nm}$ and $1576 \mathrm{~nm}$, respectively, which are normally present in graphitic materials as shown in Fig. S3, ESI. $\uparrow$ Graphite basically consists of stacks of $\mathrm{sp}^{2}$ bonded planar graphene sheets. The $\mathrm{D}$ band arises from scattering of phonons which are associated with the structural defects and the $\mathrm{G}$ band is associated with the $E_{2 g}$ species of hexagonal graphite's infinite single crystal. ${ }^{\mathbf{8 4 , 8 5}}$ Hence, Raman spectra imply the presence of graphitic structures within the nanohybrids.

To examine the conductivity of the as-prepared anode materials, electrochemical impedance spectroscopy was employed to study the electrochemical behaviour and the charge-transfer resistance. Each Nyquist curve is composed of a well-defined semicircle followed by a straight line which represents the charge transfer resistance $\left(R_{\mathrm{ct}}\right)$ and the solution resistance $\left(R_{\mathrm{S}}\right)$ at the electrode/electrolyte interface, respectively, as shown in Fig. 6..$^{\mathbf{8 6 7} 87}$

The $R_{\mathrm{ct}}$ values corresponding to the diameter of the semicircles follows the order $\mathrm{Pd}_{77} \mathrm{Fe}_{23} / \mathrm{GCN}(\sim 103$ ohms $)>\mathrm{Pd}_{85} \mathrm{Fe}_{15} /$ $\operatorname{GCN}(\sim 94 \mathrm{ohms})>\mathrm{Pd}_{100} / \mathrm{GCN}(\sim 84 \mathrm{ohms})>\mathrm{Pd}_{91} \mathrm{Fe}_{9} / \mathrm{GCN}(\sim 54$ ohms) $>\mathrm{Pd}_{96} \mathrm{Fe}_{4} / \mathrm{GCN}$ ( $\sim 41$ ohms). The $\mathrm{Pd}_{96} \mathrm{Fe}_{4} / \mathrm{GCN}$ nanohybrid exhibited much lower charge-transfer resistance, which was half that of $\mathrm{Pd}_{100} / \mathrm{GCN}$ under similar electrolyte solution and experimental conditions. This suggests the effectiveness of bimetallic Pd-Fe NPs with a particular composition in enhancing the charge transfer ability of the Pd based nanohybrid. Hence, EIS results demonstrate that charge flow between the $\mathrm{Pd}_{96} \mathrm{Fe}_{4} / \mathrm{GCN}$ electrocatalyst and electrolyte has a faster electron transfer rate that can facilitate the electrochemical oxidation of alcohol compared to the $\mathrm{Pd}_{100} / \mathrm{GCN}$.

The cyclic voltammogram (CV) profiles for the $\mathrm{Pd}_{100} / \mathrm{GCN}$, $\mathrm{Pd}_{96} \mathrm{Fe}_{4} / \mathrm{GCN}, \mathrm{Pd}_{91} \mathrm{Fe}_{9} / \mathrm{GCN}, \mathrm{Pd}_{85} \mathrm{Fe}_{15} / \mathrm{GCN}$, and $\mathrm{Pd}_{77} \mathrm{Fe}_{23} / \mathrm{GCN}$ nanohybrid based electrodes clearly display peaks for hydrogen adsorption and desorption $\left(\mathrm{H}_{\mathrm{ad}} / \mathrm{H}_{\mathrm{des}}\right)$, oxide formation, and oxide reduction. ${ }^{10}$ For $\mathrm{Pd}_{100} / \mathrm{GCN}$, a peak at around $-0.40 \mathrm{~V}$ in the first region of potential arises due to the adsorption of $\mathrm{OH}^{-}$ ions as evident from Fig. 7a.

Notably, the peak current in the region is higher for the alloys in comparison to the pure Pd indicating possible
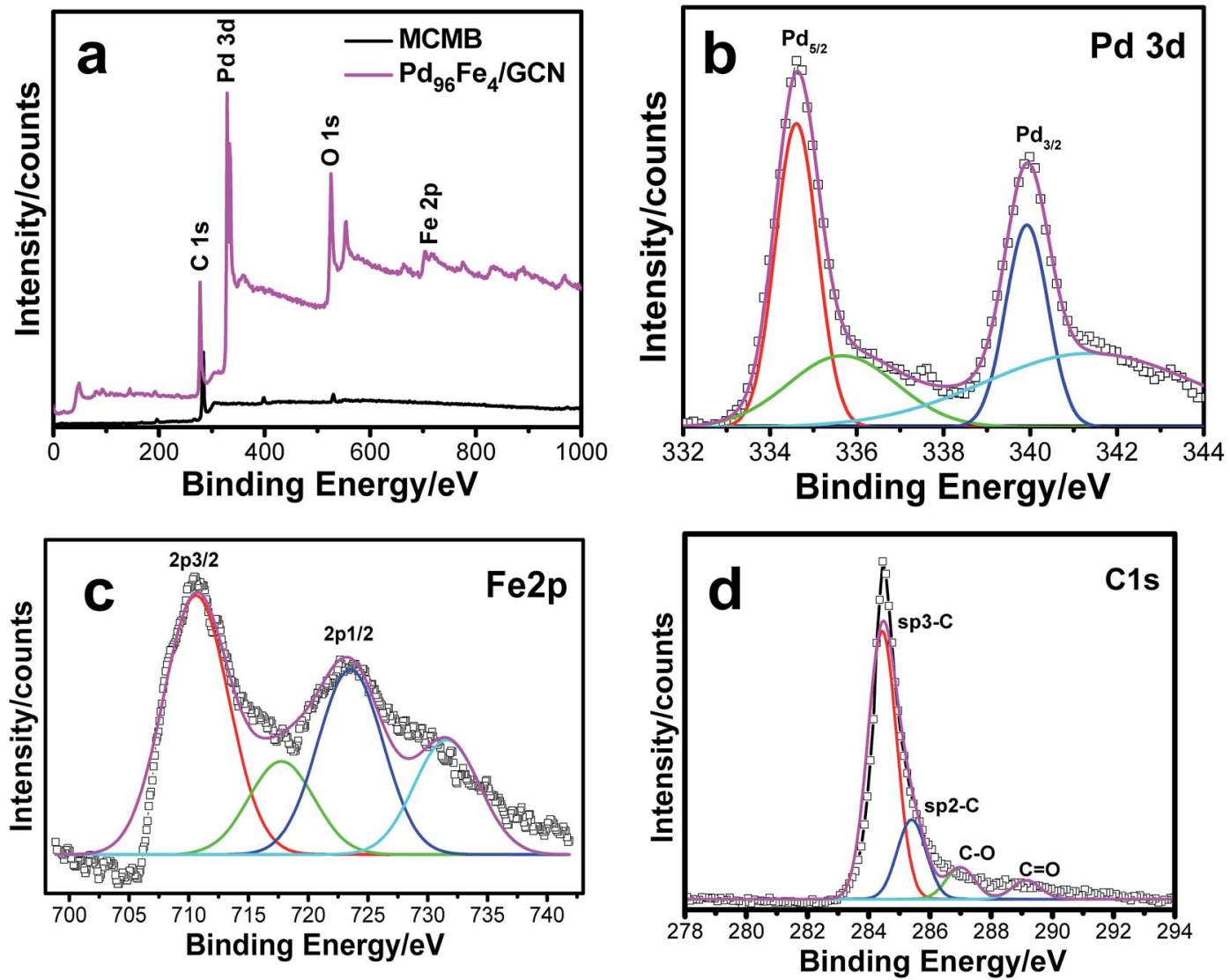

Fig. 5 (a) XPS pattern for the MCMBs and as-prepared $\mathrm{Pd}_{96} \mathrm{Fe}_{4} / \mathrm{GCN}$ nanohybrids, and (b-d) magnified XPS spectra for (b) Pd 3d, (c) Fe 2p and (d) C 1s. 


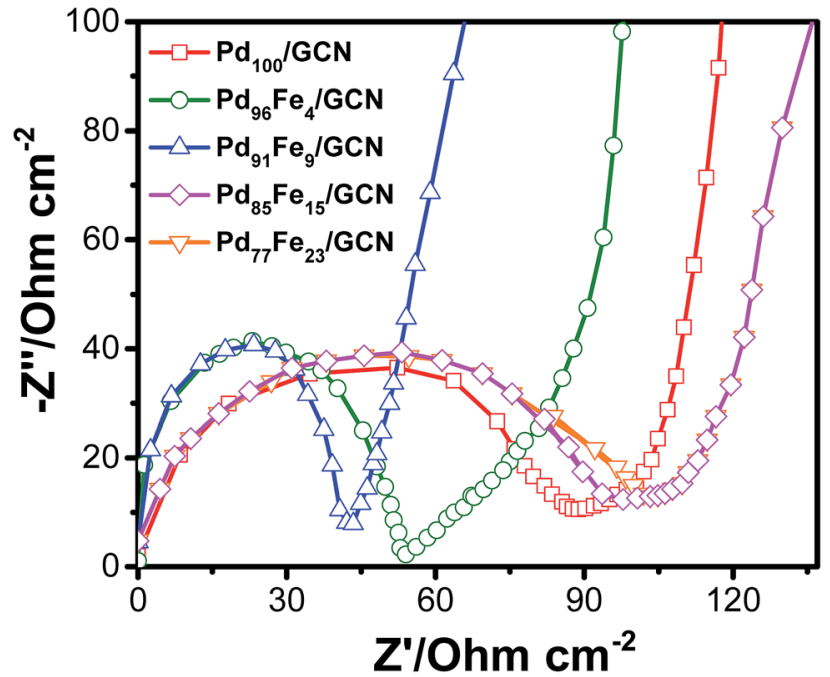

Fig. 6 Nyquist plots of the $\mathrm{Pd}_{100} / \mathrm{GCN}, \mathrm{Pd}_{96} \mathrm{Fe}_{4} / \mathrm{GCN}, \mathrm{Pd}_{91} \mathrm{Fe}_{9} / \mathrm{GCN}$, $\mathrm{Pd}_{85} \mathrm{Fe}_{15} / \mathrm{GCN}$ and $\mathrm{Pd}_{77} \mathrm{Fe}_{23} / \mathrm{GC}$ nanohybrids. Nyquist plot analysis indicates that the $\mathrm{Pd}_{96} \mathrm{Fe}_{4} / \mathrm{GCN}$ anode with small charge transfer resistance would be an outstanding anode material for DAFCs.

transmetalation reaction. ${ }^{17}$ The catalytic activity of four different compositions of $\mathrm{Pd}_{1-x} \mathrm{Fe}_{x} / \mathrm{GCN}(x$, molar ratio of $\mathrm{Fe})$ for the ethanol oxidation was evaluated in alkaline medium. The catalytic activity is highly dependent on the Pd/Fe molar ratio (Fig. $7 \mathrm{~b}$ ). The monometallic $\mathrm{Fe}_{100} / \mathrm{GCN}$ catalysts show no activity for ethanol oxidation (Fig. S4, ESI†), while the incorporation of $\mathrm{Pd}$ with $\mathrm{Fe}$ together results in a significant enhancement in catalytic activity. The ECSA of $\mathrm{Pd}_{100} / \mathrm{GCN}$, $\mathrm{Pd}_{96} \mathrm{Fe}_{4} / \mathrm{GCN}, \mathrm{Pd}_{91} \mathrm{Fe}_{9} / \mathrm{GCN}, \mathrm{Pd}_{85} \mathrm{Fe}_{15} / \mathrm{GCN}$, and $\mathrm{Pd}_{77} \mathrm{Fe}_{23} / \mathrm{GCN}$ has been calculated to be $15.6 \mathrm{~m}^{2} \mathrm{~g}^{-1}, 80.5 \mathrm{~m}^{2} \mathrm{~g}^{-1}, 28.5 \mathrm{~m}^{2} \mathrm{~g}^{-1}$, $23.5 \mathrm{~m}^{2} \mathrm{~g}^{-1}$, and $21 \mathrm{~m}^{2} \mathrm{~g}^{-1}$, respectively. The value of ECSA for $\mathrm{Pd}_{96} \mathrm{Fe}_{4} / \mathrm{GCN}$ has been found to be about 5.3 times higher than the value obtained for $\mathrm{Pd}_{100} / \mathrm{GCN}$, which may be attributed to nanodendritic structures of metal NPs, and the synergistic effects between the metal NPs and graphitic surface.

Notably, $\mathrm{Pd}_{96} \mathrm{Fe}_{4} / \mathrm{GCN}$ shows exceptionally high catalytic activity toward the electrooxidation of ethanol with a high mass activity of $11008.2 \mathrm{~mA} \mathrm{~cm}{ }^{-2} \mathrm{mg}^{-1}$, one of the highest values reported thus far (Fig. 7c and Table 1). In contrast, $\mathrm{Pd}_{100} / \mathrm{GCN}$, $\mathrm{Pd}_{91} \mathrm{Fe}_{9} / \mathrm{GCN}, \mathrm{Pd}_{85} \mathrm{Fe}_{15} / \mathrm{GCN}$, and $\mathrm{Pd}_{77} \mathrm{Fe}_{23} / \mathrm{GCN}$ display reduced activity for ethanol oxidation under similar conditions (Fig. $7 \mathrm{~b}$ and c). The catalytic performance of the catalysts follows the order $\mathrm{Pd}_{96} \mathrm{Fe}_{4} / \mathrm{GCN}$ (36-fold) $>\mathrm{Pd}_{91} \mathrm{Fe}_{9} / \mathrm{GCN}$ (15-fold) $>\mathrm{Pd}_{85} \mathrm{Fe}_{15} /$ $\operatorname{GCN}(2.7$-fold $)>\mathrm{Pd}_{77} \mathrm{Fe}_{23} / \mathrm{GCN}$ (2.3-fold) $>\mathrm{Pd}_{100} / \mathrm{GCN}$ (selected as the reference). Such remarkably high activity of Pd-Fe NPs supported on GCN is attributed to the synergistic effect between Pd and $\mathrm{Fe}$ atoms, and the strong interactions between the graphitic surface and metal species through graphene layers.

To test the durability and recyclability of the nanohybrid, the $\mathrm{Pd}_{96} \mathrm{Fe}_{4} / \mathrm{GCN}$ anode was tested at $-0.22 \mathrm{~V}$ in $0.5 \mathrm{M}$ ethanol over $3000 \mathrm{~s}$ via the chronoamperometric method (Fig. 7d). Initially, all catalysts exhibited a pronounced current decay up to $250 \mathrm{~s}$ due to accumulation of poisonous intermediates; then the current density attained a steady state for $\mathrm{Pd}_{96} \mathrm{Fe}_{4} / \mathrm{GCN}$ indicating that the $\mathrm{Pd}_{96} \mathrm{Fe}_{4} \mathrm{NPs}$ form a very stable film on the glassy carbon electrode surface and display stable electrocatalytic performance towards ethanol oxidation. However, for other electrodes, the current density significantly decayed in the first $200 \mathrm{~s}$, and finally reached the zero value. The presence of graphitic carbon nanosheets as well as assembled $\mathrm{Pd}_{96} \mathrm{Fe}_{4}$ nanoalloy structures increases the stability of the anode catalysts for ethanol oxidation. No change in catalytic activity was observed over 1000 cycles (Fig. S5, ESI†). Remarkably, XRD, SEM and TEM analyses of $\mathrm{Pd}_{96} \mathrm{Fe}_{4} / \mathrm{GCN}$ after the catalytic reaction show no significant changes in size, distribution and structure suggesting that the $\mathrm{Pd}_{96} \mathrm{Fe}_{4} / \mathrm{GCN}$ catalyst possesses high stability under the current experimental conditions (Fig. S6b-d, ESI†). The superior stability was further confirmed by inductively coupled plasma atomic emission spectroscopic (ICP-AES) analysis, where no Pd and Fe were detected in the electrolyte following ethanol electrooxidation for 1000 cycles.

In order to explore the potential applications of the asprepared catalysts, the methanol, ethylene glycol, tri-ethylene glycol, and glycerol oxidation reactions were also tested in alkaline solution. The CV profiles of all fuel oxidations display well-defined anodic peaks in the forward and reverse scans using $\mathrm{Pd}_{96} \mathrm{Fe}_{4} / \mathrm{GCN}$ as the anode catalyst (Fig. 8a-d). The highest mass activity was $11.008 \mathrm{~A} \mathrm{mg}^{-1}$ metal (normalized by the mass of metal) obtained for ethanol oxidation, followed by that for ethylene glycol oxidation using the $\mathrm{Pd}_{96} \mathrm{Fe}_{4} / \mathrm{GCN}$ electrode (Table 1). This superior catalytic activity of $\mathrm{Pd}_{96} \mathrm{Fe}_{4} / \mathrm{GCN}$ toward the ethanol oxidation reaction suggests that optimizing the alloy composition can effectively enhance the overall electrocatalytic activity of the alloy. Notably, the obtained catalytic activity of the $\mathrm{Pd}_{96} \mathrm{Fe}_{4} / \mathrm{GCN}$ is even superior to that of other Pt or Pd group-based electrocatalysts for the ethanol oxidation reaction in alkaline media (Table S2†). The significantly negative shift of the onset potential and high anodic peak current for the EOR on the $\mathrm{Pd}_{96} \mathrm{Fe}_{4} / \mathrm{GCN}$ electrode suggest outstanding electrocatalytic activity for direct ethanol fuel cells. The $\mathrm{Pd}_{96} \mathrm{Fe}_{4} /$ GCN generates a mass activity of $5.02 \mathrm{~A} \mathrm{mg}^{-1}$ metal for ethylene glycol oxidation, which is much higher than that of PdPt nanowires ${ }^{88} \mathrm{Pd}$ nanodendrites supported on reduced graphene oxide, ${ }^{89} \mathrm{Pd}-(\mathrm{Ni}-\mathrm{Zn}) / \mathrm{C},{ }^{90}$ and Pd-decorated $\mathrm{FeCo} @ \mathrm{Fe} / \mathrm{C}$ coreshell nanocatalysts, ${ }^{91}$ and is even comparable to that of trimetallic $\mathrm{Pd}-\mathrm{Au}-\mathrm{Ag}$ catalysts. ${ }^{92} \mathrm{~A}$ similar tendency is also observed for glycerol electrooxidation using the $\mathrm{Pd}_{96} \mathrm{Fe}_{4} / \mathrm{GCN}$ electrode with a mass activity of $1.86 \mathrm{~A} \mathrm{mg}^{-1}$ metal, which is much better than that of the reported PdPt nanowires, ${ }^{88}$ carbon supported Pd based core-shell nanocatalysts, ${ }^{91} \mathrm{Pd}_{x} \mathrm{Bi}$ catalysts, ${ }^{93}$ and metal oxide $\left(\mathrm{CeO}_{2}, \mathrm{NiO}, \mathrm{Co}_{3} \mathrm{O}_{4}\right.$ and $\left.\mathrm{Mn}_{3} \mathrm{O}_{4}\right)$-supported Pd catalysts. ${ }^{94}$ Similarly, other $\mathrm{Pd}-\mathrm{Fe} / \mathrm{GCN}$ catalysts were tested for oxidation of methanol, ethylene glycol, tri-ethylene glycol, and glycerol and they followed a similar trend to ethanol oxidation, except for glycerol oxidation where the current density for $\mathrm{Pd}_{85} \mathrm{Fe}_{15} /$ GCN was higher than that for $\mathrm{Pd}_{91} \mathrm{Fe}_{9} / \mathrm{GCN}$ (Table S3†). However, the current density further decreases significantly for the $\mathrm{Pd}_{77} \mathrm{Fe}_{23} / \mathrm{GCN}$ nanohybrids. In fact, $\mathrm{Pd}_{96} \mathrm{Fe}_{4} / \mathrm{GCN}$ showed high catalytic activity for oxidation of fuel such as methanol, ethylene glycol, tri-ethylene glycol, and glycerol.

Hence, $\mathrm{Pd}_{96} \mathrm{Fe}_{4} / \mathrm{GCN}$ showed the best catalytic activity among the different Pd-Fe compositions, which suggests that 

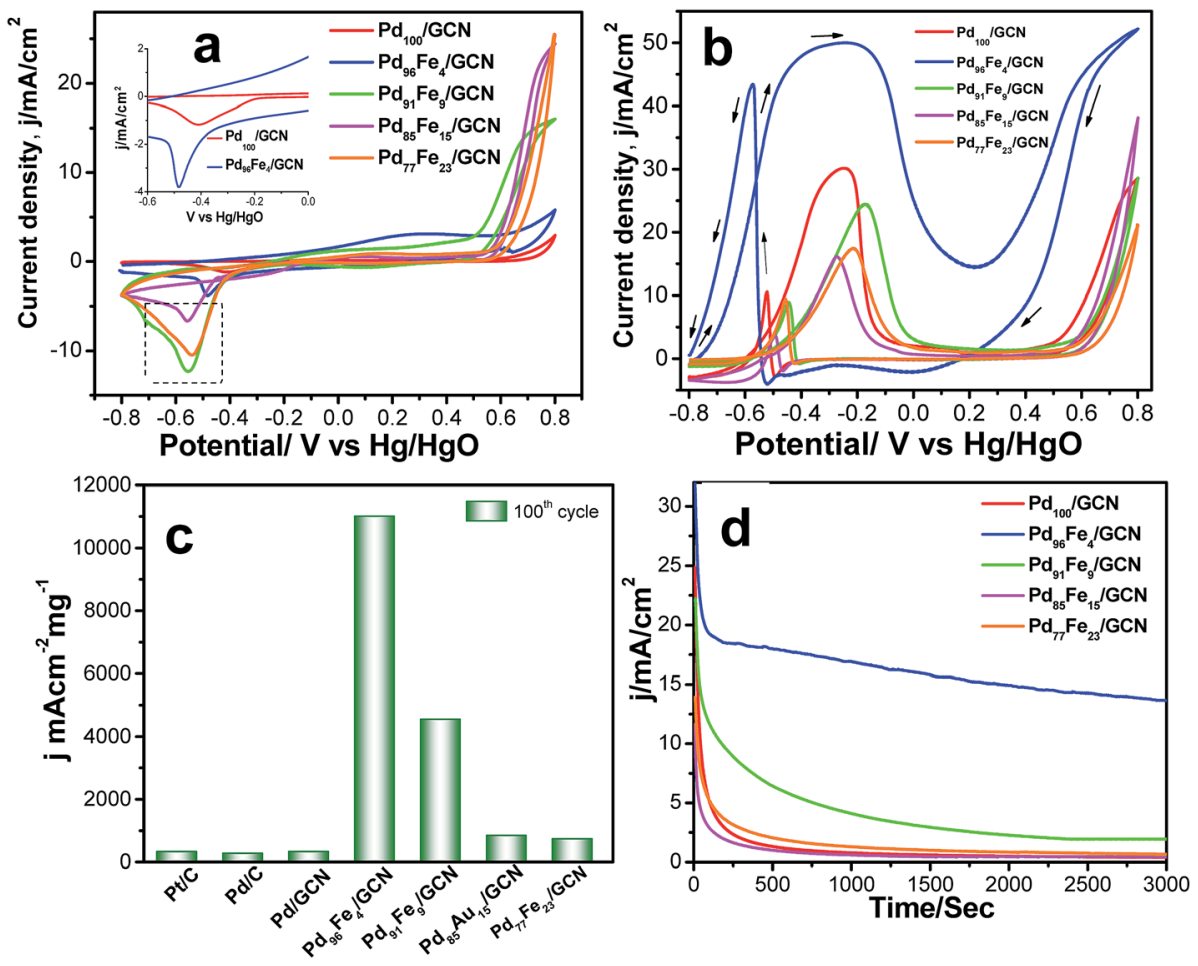

Fig. 7 (a) $\mathrm{CVs}$ of the $\mathrm{Pd}_{100} / \mathrm{GCN}, \mathrm{Pd}_{96} \mathrm{Fe}_{4} / \mathrm{GCN}, \mathrm{Pd}_{91} \mathrm{Fe}_{9} / \mathrm{GCN}, \mathrm{Pd}_{85} \mathrm{Fe}_{15} / \mathrm{GCN}$, and $\mathrm{Pd}_{77} \mathrm{Fe}_{23} / \mathrm{GCN}$ nanohybrids in $0.5 \mathrm{M} \mathrm{KOH}$ at a scan rate of $50 \mathrm{mV} \mathrm{s}^{-1}$. (b) CVs for the electrocatalytic oxidation of $0.5 \mathrm{M}$ ethanol at the $100^{\text {th }}$ cycle by $\mathrm{Pd}_{100} / \mathrm{GCN}$ (red solid line), Pd96 $\mathrm{Fe}_{4} / \mathrm{GCN}$ (blue solid line), $\mathrm{Pd}_{91} \mathrm{Fe}_{9} / \mathrm{GCN}$ (green solid line), $\mathrm{Pd}_{85} \mathrm{Fe}_{15} / \mathrm{GCN}$ (pink solid line), and $\mathrm{Pd}_{77} \mathrm{Fe}_{23} / \mathrm{GCN}$ (orange solid line) nanohybrids at a scan rate of $50 \mathrm{mV} \mathrm{s}^{-1}$ in $0.5 \mathrm{M} \mathrm{KOH}$. (c) Comparative values of mass activity of Pd/C, Pd/C, $\mathrm{Pd}_{100} / \mathrm{GCN}, \mathrm{Pd}_{96} \mathrm{Fe}_{4} / \mathrm{GCN}, \mathrm{Pd}_{91} \mathrm{Fe}_{9} / \mathrm{GCN}_{1} \mathrm{Pd}_{85} \mathrm{Fe}_{15} / \mathrm{GCN}$, and Pd $77 \mathrm{Fe}_{23} / \mathrm{GCN}$ electrodes for ethanol oxidation in alkaline medium. (d) Chronoamperometric curves for the ethanol oxidation at a constant potential of $-0.22 \mathrm{~V}$ vs. $\mathrm{Hg} / \mathrm{HgO}$ on $\mathrm{Pd}_{100} / \mathrm{GCN}, \mathrm{Pd}_{96} \mathrm{Fe}_{4} / \mathrm{GCN}, \mathrm{Pd}_{91} \mathrm{Fe}_{9} / \mathrm{GCN}, \mathrm{Pd}_{85} \mathrm{Fe}_{15} / \mathrm{GCN}$, and $\mathrm{Pd}_{77} \mathrm{Fe}_{23} / \mathrm{GCN}$ electrodes.

the introduction of Fe to form a binary system would allow gaining exceptionally high catalytic activity and stability. Among the Pd-Fe/GCN catalysts, such high catalytic activity of the $\mathrm{Pd}_{96} \mathrm{Fe}_{4} / \mathrm{GCN}$ catalyst may have originated from its porous structure, large surface area, and in particular the small size of each individual branch in the dendrites, which are required for a good catalyst. ${ }^{38,39}$ It may also be inferred that the substantially shorter metal-metal distances in the bimetallic nanoalloy catalysts and modification of the electronic structure of metals are responsible for their substantially improved catalytic properties, which is well consistent with the reported literature. ${ }^{22}$ Furthermore, the presence of $\mathrm{Fe}$ metal may contribute to the increase of resistance to poisoning of the Pd based catalytic surface with adsorption of chemical species as reported earlier. ${ }^{20,95,96}$ Additionally, the highly active sites and large effective surface area of carbon nanosheets with a graphene-like layered structure shorten paths for fast electrolyte ion diffusion, consequently offering

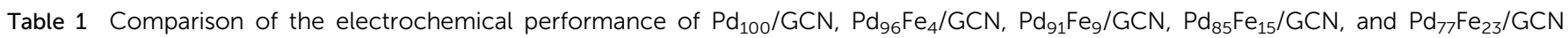
nanohybrids for the alcohol oxidation in alkaline medium

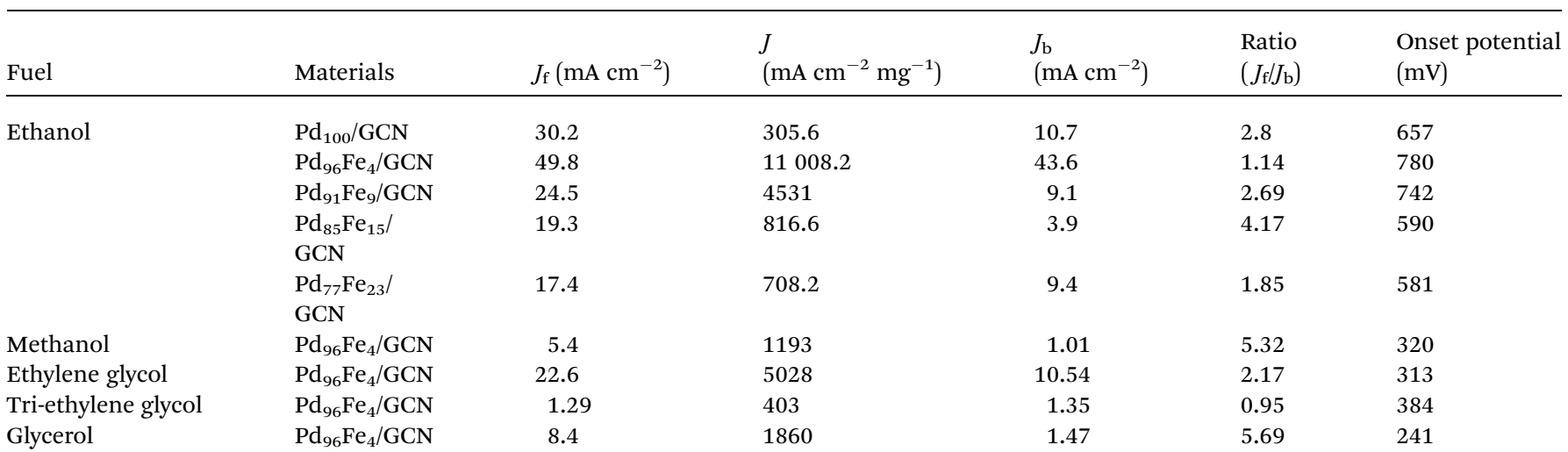



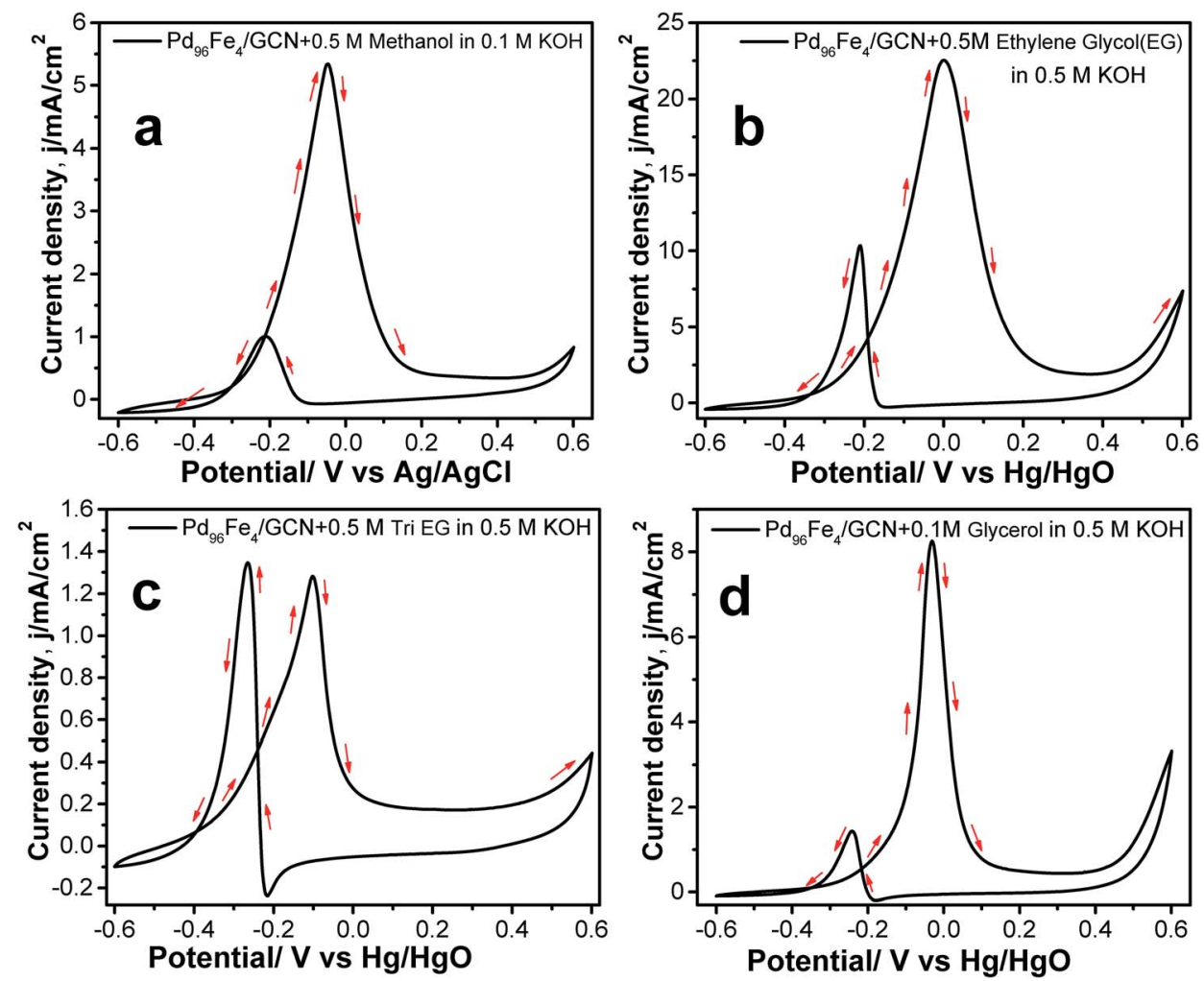

Fig. $8 \mathrm{CVs}$ for the electrocatalytic oxidation of (a) $0.5 \mathrm{M}$ methanol in $0.1 \mathrm{M} \mathrm{KOH}$, (b) $0.5 \mathrm{M}$ ethylene glycol, (c) $0.5 \mathrm{M}$ tri-ethylene glycol, and (d) $0.5 \mathrm{M}$ glycerol at the $100^{\text {th }}$ cycle by $\mathrm{Pd}_{96} \mathrm{Fe}_{4} / \mathrm{GCN}$ in $0.5 \mathrm{M} \mathrm{KOH}$ at a scan rate of $50 \mathrm{mV} \mathrm{s}^{-1}$.

more electron/charge transfer channels within the nanohybrid materials during catalysis. ${ }^{97-99}$ Furthermore, the combination of graphitic nanosheets with metal nanostructures leads to the protection of the metal nanocluster from further aggregation and provides superior catalytic activity, and can be extended as a scalable, clean approach without using any chemical reducing agents via radiolysis.

During ethanol oxidation, initially ethanol may adsorb on the electrode surface followed by oxidation and decomposition to generate intermediates such as acetate $\left(\mathrm{CH}_{3} \mathrm{COO}^{-}\right)$, acetaldehyde $\left(\mathrm{CH}_{3} \mathrm{CHO}\right)$, and $\mathrm{CO}^{5}$ In order to shed light on anodic oxidation of ethanol, a cyclic voltammetric study was carried out using $\mathrm{Pd}_{96} \mathrm{Fe}_{4} / \mathrm{GCN}$ electrodes immersed in $0.5 \mathrm{M} \mathrm{KOH}$ with sodium acetate, acetaldehyde and ethanol fuels $(100 \mathrm{mM})$. Product analysis reveals that both acetaldehyde and acetate exist after electrooxidation of ethanol (Fig. S7, ESI $†$ ). Our preliminary results suggest that the oxide species adsorbed on the $\mathrm{Pd}_{96} \mathrm{Fe}_{4} / \mathrm{GCN}$ surface and $\mathrm{Pd}$ are converted into PdO due to $\mathrm{CO}$ being adsorbed, which could easily be desorbed to restore the active sites of Pd through transmetallation reaction between $\mathrm{Pd}$ and Fe. The regeneration of Pd active sites enhances ethanol oxidation and diminishes CO poisoning.

\section{Conclusion}

We have successfully demonstrated the simultaneous formation of graphitic nanosheets and deposition of homogeneously alloyed Pd and Fe bimetallic particles through radiolysis without using any additional stabilizing agents. The chemical composition and morphology of the Pd-Fe nanoalloy can be tuned by varying the initial concentration of Fe precursors. Transmission electron microscopy analysis reveals that the nanoparticles are strongly attached to the GCN surface, which makes the NP surface available for electrochemical reactions. Remarkably, the as-prepared $\mathrm{Pd}_{96} \mathrm{Fe}_{4} / \mathrm{GCN}$ catalyst exhibits extremely high catalytic activity for ethanol oxidation with high current density. The exceptionally high catalytic activity of $\mathrm{Pd}_{96} \mathrm{Fe}_{4} / \mathrm{GCN}$ could be mainly attributed to the strong synergistic effect between Pd and Fe atoms, and the large surface area of the 2D graphitic carbon nanosheet structures, which are enabled by enhancing the interactions between the graphene surface and metal species. The easy fabrication, cost-effectiveness, high intrinsic activity, and superior stability make the $\mathrm{Pd}-\mathrm{Fe} / \mathrm{GCN}$ nanohybrid a very promising catalyst for the electrochemical oxidation of alcohol. The present strategy would be useful to fabricate other graphitic carbon nanosheet supported multimetallic nanoalloys as superior anode catalysts for DAFC applications.

\section{Conflicts of interest}

There are no conflicts to declare.

\section{References}

1 S. K. Kamarudin, F. Achmad and W. R. W. Daud, Int. J. Hydrogen Energy, 2009, 34, 6902-6916. 
2 E. Antolini and E. R. Gonzalez, J. Power Sources, 2010, 195, 3431-3450.

3 S. P. S. Badwal, S. Giddey, A. Kulkarni, J. Goel and S. Basu, Appl. Energy, 2015, 145, 80-103.

4 W. Yu, M. D. Porosoff and J. G. Chen, Chem. Rev., 2012, 112, 5780-5817.

5 S. Ghosh, M. Thandavarayan and R. N. Basu, Recent advances in nanostructured electrocatalysts for direct alcohol fuel cells, in Electrocatalysts for low temperature fuel cells-fundamentals and recent trends, Wiley-VCH Verlag Gmbh \& Co. KGaA, Germany, 2017, ch. 11, pp. 347-372.

6 S. Ghosh, P. Kar, N. Bhandary, S. Basu, S. Sardar, T. Maiyalagan, D. Majumdar, S. K. Bhattacharya, A. Bhaumik, P. Lemmens and S. K. Pal, Catal. Sci. Technol., 2016, 6, 1417-1429.

7 H. A. Gasteiger and N. M. Markovic, Science, 2009, 3, 48-49. 8 F. Vigier, S. Rousseau, C. Coutanceau, J.-M. Leger and C. Lamy, Top. Catal., 2006, 40, 111-121.

9 F. Ksar, L. Ramos, B. Keita, L. Nadjo, P. Beaunier and H. Remita, Chem. Mater., 2009, 21, 3677-3683.

$10 \mathrm{~S}$. Ghosh, N. Bhandary, S. Basu and R. N. Basu, Electrocatalysis, 2017, 8, 329-339.

11 S. Ghosh, A.-L. Teillout, D. Floresyona, P. de Oliveira, A. Hagège and H. Remita, Int. J. Hydrogen Energy, 2015, 40, 4951-4959.

12 S. Ghosh, H. Remita, P. Kar, S. Choudhury, S. Sardar, P. Beaunier, P. S. Roy, S. K. Bhattacharya and S. K. Pal, J. Mater. Chem. A, 2015, 3, 9517-9527.

13 H. J. You, S. C. Yang, B. J. Ding and H. Yang, Chem. Soc. Rev., 2013, 42, 2880-2904.

14 J. Gu, Y. W. Zhang and F. Tao, Chem. Soc. Rev., 2012, 41, 8050-8065.

15 S. R. Chowdhury, S. Ghosh and S. K. Bhattachrya, Electrochim. Acta, 2017, 225, 310-321.

16 S. Guo, S. Dong and E. Wang, Energy Environ. Sci., 2010, 3, 1307-1310.

17 M. S. Ahmed and S. Jeon, J. Electrochem. Soc., 2014, 161, F1300-F1306.

18 M. Li, D. A. Cullen, K. Sasaki, N. S. Marinkovic, K. More and R. R. Adzic, J. Am. Chem. Soc., 2013, 135, 1132-1141.

19 S. Ghosh, S. Bera, S. Bysakh and R. N. Basu, Sustainable Energy Fuels, 2017, 1, 1148-1161.

20 L. Wang, Y. Nemoto and Y. Yamauchi, J. Am. Chem. Soc., 2011, 133, 9674-9677.

21 J. Xue, G. Han, W. Ye, Y. Sang, H. Li, P. Guo and X. Zhao, ACS Appl. Mater. Interfaces, 2016, 8, 34497-34505.

22 S. Ghosh, S. Bera, S. Bysakh and R. N. Basu, ACS Appl. Mater. Interfaces, 2017, 9, 33775-33790.

23 S.-C. Hsu, Y.-C. Chuang, B. T. Sneed, D. A. Cullen, T.-W. Chiu and C.-H. Kuo, Nano Lett., 2016, 16, 5514-5520.

24 J. N. Tiwari, W. G. Lee, S. Sultan, M. Yousuf, A. M. Harzandi, V. Vij and K. S. Kim, ACS Nano, 2017, 11, 7729-7735.

25 X. Yan, S. Yu, Y. Tang, D. Sun, L. Xu and C. Xue, Nanoscale, 2018, 10, 2231-2235.

26 Y. W. Lee, M. Im, J. W. Hong and S. W. Han, ACS Appl. Mater. Interfaces, 2017, 9, 44018-44026.
27 G. Ren, Y. Liu, W. Wang, M. Wang, Z. Zhang, Y. Liang, S. Wu and J. Shen, ACS Appl. Nano Mater., 2018, 1, 3226-3235.

28 L. Wang and Y. J. Yamauchi, J. Am. Chem. Soc., 2010, 132, 13636-13638.

29 N. Zhang, S. Guo, X. Zhu, J. Guo and X. Huang, Chem. Mater., 2016, 28, 4447-4452.

30 X.-J. Liu, C.-H. Cui, H.-H. Li, Y. Lei, T.-T. Zhuang, M. Sun, M. N. Arshad, H. A. Albar, T. R. Sobahi and S.-H. Yu, Chem. Sci., 2015, 6, 3038-3043.

31 B. Jiang, C. Li, V. Malgras and Y. Yamauchi, J. Mater. Chem. A, 2015, 3, 18053-18058.

32 W. Du, K. E. Mackenzie, D. F. Milano, N. A. Deskins, D. Su and X. Teng, ACS Catal., 2012, 2, 287-297.

33 K. Jiang, P. Wang, S. Guo, X. Zhang, X. Shen, G. Lu, D. Su and X. Huang, Angew. Chem., Int. Ed., 2016, 55, 9030-9035.

34 S. Sankar, G. M. Anilkumar, T. Tamaki and T. Yamaguchi, ACS Appl. Energy Mater., 2018, 1, 4140-4149.

35 H. Xu, P. P. Song, Y. P. Zhang and Y. K. Du, Nanoscale, 2018, 10, 12605-12611.

36 S. Guo and S. Sun, J. Am. Chem. Soc., 2012, 134, 2492-2495.

37 B. A. Al-Qodami, H. H. Farrag, S. Y. Sayed, N. K. Allam, B. E. El-Anadouli and A. M. Mohammad, J. Nanotechnol., 2018, 1-10.

38 D.-Y. Wang, H.-L. Chou, C.-C. Cheng, Y.-H. Wu, C.-M. Tsai, H.-Y. Lin, Y.-L. Wang, B.-J. Hwang and C.-C. Chen, Nano Energy, 2015, 11, 631-639.

39 P. Song, H. Xu, J. Wang, Y. Zhang, F. Gao, J. Guo, Y. Shiraishic and Y. Du, Nanoscale, 2018, 10, 16468-16473.

40 S. Guo, S. Dong and E. Wang, ACS Nano, 2009, 4, 547-555.

41 E. Ye, M. D. Regulacio, S. Y. Zhang, X. J. Loh and M. Y. Han, Chem. Soc. Rev., 2015, 44, 6001-6017.

42 J. Bai, X. Xiao, Y.-Y. Xue, J.-X. Jiang, J.-H. Zeng, X.-F. Li and Y. Chen, ACS Appl. Mater. Interfaces, 2018, 10, 19755-19763.

43 L. L. Zhang and X. Zhao, Chem. Soc. Rev., 2009, 38, 25202531.

44 H. Huang and X. Wang, J. Mater. Chem. A, 2014, 2, 62666291.

45 M. S. Ahmed and S. Jeon, J. Power Sources, 2015, 282, 479488.

46 M. Liu, R. Zhang and W. Chen, Chem. Rev., 2014, 114, 51175160.

47 R. Krishna, D. M. Fernandes, A. Marinoiu, J. Ventura, C. Freire and E. Titus, Int. J. Hydrogen Energy, 2017, 42, 23639-23646.

48 R. Krishna, D. M. Fernandes, J. Ventura, C. Freire and E. Titus, Int. J. Hydrogen Energy, 2016, 41, 11811-11822.

49 X. Chen, Z. Cai, X. Chen and M. Oyama, J. Mater. Chem. A, 2014, 2, 315-320.

50 X. Yang, Q. Yang, J. Xu and C. S. Lee, J. Mater. Chem. A, 2012, 22, 8057-8062.

51 F. Ren, H. Wang, C. Zhai, M. Zhu, R. Yue, Y. Du, P. Yang, J. Xu and W. Lu, ACS Appl. Mater. Interfaces, 2014, 6, 36073614.

52 F. Ren, C. Wang, C. Zhai, F. Jiang, R. Yue, Y. Du, P. Yang and J. Xu, J. Mater. Chem. A, 2013, 1, 7255-7261.

53 C. G. Hu, H. H. Cheng, Y. Zhao, Y. Hu, Y. Liu, L. M. Dai and L. T. Qu, Adv. Mater., 2012, 24, 5493-5498. 
54 M. M. Liu, Y. Z. Lu and W. Chen, Adv. Funct. Mater., 2013, 23, 1289-1296.

55 R. Awasthi and R. N. Singh, Catal. Sci. Technol., 2012, 2, 2428-2432.

56 S. Ghosh, Y. Holade, H. Remita, K. Servat, P. Beaunier, A. Hagège, B. Kokoh and T. W. Napporn, Electrochim. Acta, 2016, 212, 864-875.

57 W. Lv, D. M. Tang, Y. B. He, C. H. You, Z. Q. Shi, X. C. Chen, C. M. Chen, P. X. Hou, C. Liu and Q. H. Yang, ACS Nano, 2009, 3, 3730-3736.

58 T. Torres, Chem. Soc. Rev., 2017, 46, 4385-4386.

59 B. B. Wang, K. Ostrikov, T. van der Laan, K. Zheng, J. J. Wang, Y. P. Yan and X. J. Quan, J. Mater. Chem. C, 2013, 1, 7703-7708.

60 A. H. Khan, S. Ghosh, B. Pradhan, A. Dalui, L. K. Shrestha, S. Acharya and K. Ariga, Bull. Chem. Soc. Jpn., 2017, 90, 1-21. 61 A. Kumar and Q. Xu, ChemNanoMat, 2018, 4, 28-40.

62 X. He, H. Ma, J. Wang, Y. Xie, N. Xiao and J. Qiu, J. Power Sources, 2017, 357, 41-46.

63 L. Chen, S. Yang, J. Huang, W. Xie, B. Ding, Y. Liu, F. Xu and Y. Liang, Mater. Lett., 2018, 232, 187-190.

64 W. Liu, T. Dang, Z. Xiao, X. Li, C. Zhu and X. Wang, Carbon, 2011, 49, 884-889.

65 F. Qi, Z. Xia, R. Sun, X. Sun, X. Xu, W. Wei, S. Wang and G. Sun, J. Mater. Chem. A, 2018, 6, 14170-14177.

66 S. Ahamad, M. Ahmad, B. R. Mehta and A. Gupta, J. Electrochem. Soc., 2017, 164, A2967-A2976.

67 A. S. Wotango, W.-N. Su, E. G. Leggesse, A. M. Haregewoin, M.-H. Lin, T. A. Zegeye, J.-H. Cheng and B.-J. Hwang, ACS Appl. Mater. Interfaces, 2017, 9, 2410-2420.

68 J. Belloni, M. Mostafavi, H. Remita, J.-L. Marignier and M. O. Delcourt, New J. Chem., 1998, 22, 1239-1255.

69 J. Grand, S. R. Ferreira, V. de Waele, S. Mintova and T. M. Nenoff, J. Phys. Chem. C, 2018, 122, 12573-12588.

70 J. Belloni, Catal. Today, 2006, 113, 141-156.

$71 \mathrm{~J}$. Belloni and M. Mostafavi, Radiation Chemistry of Nanocolloids and Clusters, in Radiation Chemistry: Present Status and Future Trends, ed. C. D. Jonah and B. S. M. Rao, Elsevier, New York, 2001, p. 411.

72 Z. Zhang, T. M. Nenoff, K. Leung, S. Ferreira, J. Huang, D. T. Berry, P. P. Provencio and R. J. Stump, J. Phys. Chem. C, 2010, 114, 14309-14318.

73 A. Abedini, A. R. Daud, M. A. A. Hamid and N. K. Othman, PLoS One, 2014, 9, e90055.

74 B. K. Sharma and K. Sahul, Radiat. Phys. Chem., 1977, 20, 341-346.

75 T. Redjala, G. Apostolecu, P. Beaunier, M. Mostafavi, A. Etcheberry, D. Uzio, C. Thomazeau and H. Remita, New J. Chem., 2008, 32, 1403-1408.

76 K. Sato, T. J. Konno and Y. Hirotsu, J. Appl. Phys., 2009, 105, 034308.
77 K. Sato and Y. Hirotsu, J. Appl. Phys., 2003, 93, 6291.

78 W. Xiao, W. Lei, J. Wang, G. Gao, T. Zhao, M. A. L. Cordeiro, R. Lin, M. Gong, X. Guo, E. Stavitski, H. L. Xin, Y. Zhu and D. Wang, J. Mater. Chem. A, 2018, 6, 11346-11352.

79 C. Norfolk, A. Kaufmann, A. Mukasyan and A. Varma, Carbon, 2006, 44, 301-306.

80 R. W. Wunder and J. Philips, J. Phys. Chem., 1996, 100, 14430-14436.

81 Y. Hou, H. Kondoh, T. Kogure and T. Ohta, Chem. Mater., 2004, 16, 5149-5152.

82 J. Baltrusaitis, D. M. Cwiertnya and V. H. Grassian, Phys. Chem. Chem. Phys., 2007, 9, 5542-5554.

83 L. Lin, Q. Zhu and A.-W. Xu, J. Am. Chem. Soc., 2014, 136, 11027-11033.

84 M. Endo, C. Kim, T. Karaki, T. Tamaki, Y. Nishimura, M. J. Matthews, S. D. M. Brown and M. S. Dresselhaus, Phys. Rev. B: Condens. Matter Mater. Phys., 1982, 58, 8991.

85 A. C. Ferrari, Solid State Commun., 2007, 143, 47-57.

86 Z. He and F. Mansfeld, Energy Environ. Sci., 2009, 2, 215-219.

87 P. M. Gomadam and J. W. Weidnern, Int. J. Energy Res., 2005, 29, 1133-1151.

88 W. Hong, C. Shang, J. Wang and E. Wang, Energy Environ. Sci., 2015, 8, 2910-2915.

89 S.-S. Li, Y.-Y. Hu, J.-J. Feng, Z.-Y. Lv, J.-R. Chen and A.-J. Wang, Int. J. Hydrogen Energy, 2014, 39, 3730-3738.

90 A. Marchionni, M. Bevilacqua, C. Bianchini, Y. X. Chen, J. Filippi, P. Fornasiero, A. Lavacchi, H. Miller, L. Q. Wang and F. Vizza, ChemSusChem, 2013, 6, 390.

91 O. O. Fashedemi and K. I. Ozoemena, Electrochim. Acta, 2014, 128, 279-286.

92 F. Wang, H. Xue, Z. Tian, W. Xing and L. Feng, J. Power Sources, 2018, 375, 37-42.

93 H. Xu, J. Wang, B. Yan, S. Li, C. Wang, Y. Shiraishi, P. Yang and Y. Du, Nanoscale, 2017, 9, 17004-17012.

94 A. Zalineeva, A. Serov, M. Padilla, U. Martinez, K. Artyushkova, S. Baranton, C. Coutanceau and P. B. Atanassov, J. Am. Chem. Soc., 2014, 136, 3937-3945.

95 C. Xu, Z. Tian, P. Shen and S. P. Jiang, Electrochim. Acta, 2008, 53, 2610-2618.

96 W. J. Huang, X. Y. Ma, H. Wang, R. F. Feng, J. G. Zhou, P. N. Duchesne, P. Zhang, F. J. Chen, N. Han, F. P. Zhao, J. H. Zhou, W. B. Cai and Y. G. Li, Adv. Mater., 2017, 29, 1703057.

97 M. Choi, K. Na, J. Kim, Y. Sakamoto, O. Terasaki and R. Ryoo, Nature, 2009, 461, 246-249.

98 F. Wang, B. Fang, X. Yu and L. Feng, ACS Appl. Mater. Interfaces, 2019, 119, 9496-9503.

99 H. Liu, D. Yang, Y. Bao, X. Yu and L. Feng, J. Power Sources, 2019, 434, 226754. 